\title{
An Analysis of Rocket Propulsion Testing Costs
}

\author{
Carmen Ramirez ${ }^{*}$ and Shamim Rahman, $\mathrm{PhD}^{\dagger}$ \\ NASA \\ Stennis Space Center, Mississippi
}

\begin{abstract}
The primary mission at NASA Stennis Space Center (SSC) is rocket propulsion testing. Such testing is commonly characterized as one of two types: production testing for certification and acceptance of engine hardware, and developmental testing for prototype evaluation or research and development $(\mathrm{R} \& D)$ purposes.

For programmatic reasons there is a continuing need to assess and evaluate the test costs for the various types of test campaigns that involve liquid rocket propellant test articles. Presently, in fact, there is a critical need to provide guidance on what represents a best value for testing and provide some key economic insights for decision-makers within NASA and the test customers outside the Agency.

Hence, selected rocket propulsion test databases and references have been evaluated and analyzed with the intent to discover correlations of technical information and test costs that could help produce more reliable and accurate cost projections in the future.

The process of searching, collecting, and validating propulsion test cost information presented some unique obstacles which then led to a set of recommendations for improvement in order to facilitate future cost information gathering and analysis.

In summary, this historical account and evaluation of rocket propulsion test cost information will enhance understanding of the various kinds of project cost information; identify certain trends of interest to the aerospace testing community.
\end{abstract}

\section{Nomenclature}

CDW
DOD
FY
GG
LRE
NASA
PB
PPA
PRD
$R^{2}$
R\&D
RPT
SAA
SSC
STE
TA
TCA

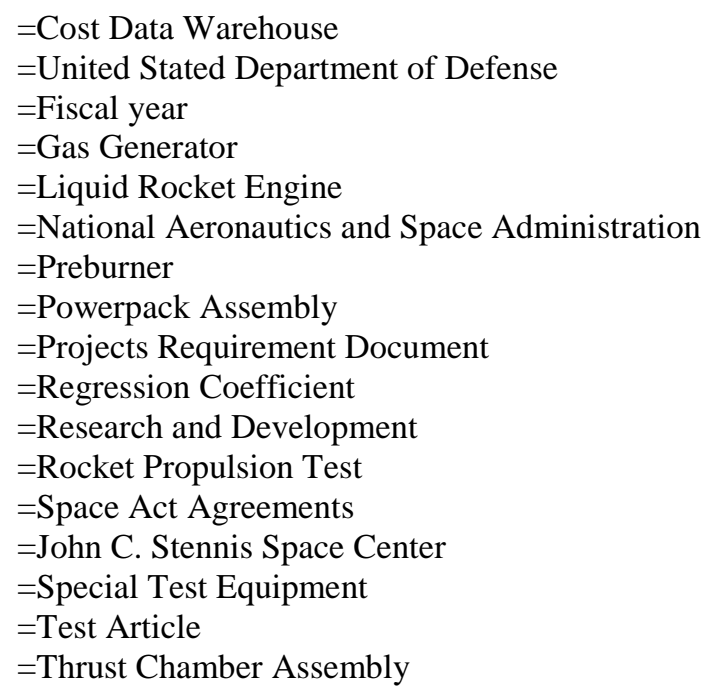

\footnotetext{
*General Engineer, Center Operations, NASA Stennis Space Center (SSC), MS, 39529.

${ }^{\dagger}$ Deputy Director, Engineering \& Test, NASA SSC, MS, 39529, AIAA Associate Fellow.
} 


\section{Purpose}

$\mathrm{T}$

he primary mission at NASA SSC is rocket propulsion testing. Such testing is often characterized as one of two types:

1. production testing for certification and acceptance of flight liquid rocket engines (LRE), and

2. developmental testing for prototype evaluation or R\&D purposes.

The traditional customer base for rocket testing consists of NASA, DOD, and commercial (non-government) programs/projects. Resources in place to perform on-site rocket testing include civil servants and contractor personnel, hardware and software including data acquisition and control across seven (7) test stands comprising a total of 11 test positions/cells. For programmatic reasons there is a continuing need to survey and evaluate the test costs for the various types of test campaigns that involve liquid rocket propellant test articles. Presently, in fact, there is a critical need to provide guidance on what represents a best value for testing and provide some key economic insights for decision-makers within NASA and the test customers outside the Agency.

Hence, selected rocket propulsion test databases and references have been evaluated and analyzed with the intent to discover correlations of technical information with test costs; this could help produce more reliable and accurate cost projections in the future.

\section{Background and Context}

\section{A. Chemical Propellant Rocket Test Capabilities}

Test facilities at SSC are comprised of three (3) rocket propulsion test complexes namely A, B, and $\mathrm{E}^{1}$ complemented by engineering analysis and specialized laboratory services as well as specialized skills/crafts capacities. Test capabilities are for full scale launch vehicle stages, full scale rocket engines/motors, small and large scale engine components (pumps, preburners, gas generators, powerheads), and small to medium combustion devices. SSC is featured alongside the rest of NASA's primary test capabilities at the official agency website for rocket testing (http://rockettest.nasa.gov/). Further details on test stands and projects have been discussed in prior conference papers (Taylor et al. ${ }^{2}$, Ryan et al. ${ }^{3}$, and Rahman et al. ${ }^{4}$ ) and are not repeated here.

For the ensuing discussion, it is important to delineate at the outset that testing involves a substantial period of pre-test preparations (weeks to months, sometimes years), and a distinct period when the visible test campaign is actually accomplished which is generally much shorter. During the preparation period, several key long-lead items are procured in parallel to a detailed design effort that specifies the special test equipment (STE) to be used, builds it up and installs it, and conducts a formal pre-test "dress rehearsal" to ensure the proper test sequences and abort modes. As will be described in this paper, the accrual of test costs occurs substantially throughout the period, and not just during the relatively brief test campaign itself.

\section{B. Prior NASA SSC Testing Cost and Technical Evaluations}

Earlier work to analyze, explain and forecast propulsion test projects cost was performed by Savona et al. ${ }^{5}$ and focused on monthly and cumulative expenditure (both planned and actual) as a function of time. The time history charts thus derived for planned expenditure were driven by the financial cycle and budget planning milestones per projected funds availability. In contrast, the time history for actual expenditure reflected funds authorization and availability. The timeline charts for cumulative expenditure exhibited no common pattern. Mathematical correlations were explored for both actual and cumulative expenditure; however, the regression coefficient $\left(R^{2}\right)$ ranged widely from 0.05 to 0.99 suggesting only limited success. Visual inspection of the timeline charts and mathematical correlations when grouped by certain criteria (i.e., project years, test stand, and timeframe) produced no consistent pattern.

In early 2002, Congiardo ${ }^{6}$ charted the cost estimates developed by NASA test engineers as preliminary estimates submitted to test customers. This study correlated the estimates against test stand, thrust level, STE complexity, test activity and so forth. Albeit cursory in nature, the review of over 30 estimates pointed out to thrust scale, STE complexity, and test activity amount as drivers of cost.

A liquid rocket testing study ${ }^{7}$ described the uniqueness of several propulsion test projects and the overall steps taken to bring them to successful completion. A corner stone for rocket engine development was a sound risk mitigation strategy through phases of ground testing within reasonable cost and schedule constraints. Despite the specialized nature of propulsion R\&D, all such projects undergo similar developmental stages of testing: subscale component test, full scale component test, "battleship" engine test, flight engine development test, flight engine 
qualification/certification/acceptance test, and flight stage qualification/acceptance test. Notably, all test projects in the above phases still share the essential common process steps: 1) test project formulation, 2) special test equipment design and engineering, 3) hardware and software modifications, 3) operational activities/test data reviews, 4) test final report and test article shipment, and 5) demobilization and project close out (and potential follow-on). Over time, as more test projects are completed, the test facilities/infrastructure/resources mature and become better equipped to serve the next project in line, thus reducing the amount of future investments to assure test success.

\section{Test Project Information Grouping}

In order to construct a comprehensive historical timeline, including a given project's costs and schedules, it was necessary to gather information from a variety of sources. The wide varieties of projects are also better understood if assembled into subsets of logical groupings. The initial guide for grouping was developed by Kirchner et al. $^{8}$ In particular; a proposed grouping by test article type and its associated thrust-scale is given in Table 1 taken

Table 1. Post-Apollo SSC propulsion test projects by test article, type and size (as of Dec. 31, 2004)

\begin{tabular}{|c|c|c|c|c|}
\hline & $\leq 1 \mathrm{Klbf}$ & $\leq 10 \mathrm{Klbf}$ & $\leq 100 \mathrm{Klbf}$ & $\leq 1 \mathrm{Mlbf}$ \\
\hline $\begin{array}{l}\text { Thrust Chamber } \\
(\mathrm{TCA}), \text { or } \\
\text { Preb (PB), or Gas } \\
\text { Gen (GG) } \\
\text {-- pressure-fed }\end{array}$ & 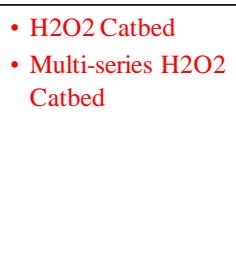 & $\begin{aligned} \cdot & 10 \mathrm{~K} \text { H2O2/JP TCA } \\
\cdot & \mathrm{H} 2 \mathrm{O} 2 / \mathrm{JP} T C A \\
& (10 \mathrm{~K}) \\
\cdot & 10 \mathrm{~K} \text { LOX Hybrids } \\
\cdot & 10 \mathrm{~K} \text { H2O } 2 \text { Hybrids }\end{aligned}$ & $\begin{array}{l}\cdot \text { - } 60 \mathrm{~K} \text { LOX Hybrid } \\
\cdot 75 \mathrm{~K} \text { LOX/RPTCA } \\
\cdot \text { RS76 LOX/RPPB (30K) } \\
\cdot \text { RS84 subscale PB (30K) } \\
\cdot \text { RS84 subscale PB/MCC }\end{array}$ & $\begin{array}{l}\text { - } 650 \mathrm{~K} \text { LOX/LH TCA } \\
\text { - } 250 \mathrm{~K} \text { LOX Hybrid Motor } \\
\text { - } 400 \mathrm{~K} \text { O2/H2 PB } \\
\text { (cancelled) } \\
\cdot \text { - } 400 \mathrm{~K} \mathrm{~PB} \mathrm{(400K} \mathrm{-cancelled)} \\
\cdot 1 \mathrm{Mlbf} \text { LOX/RP } \\
\text { Battleship PB (cancelled) }\end{array}$ \\
\hline Pump (Cold) & & & $\begin{array}{l}\text { - MK67 (12K -cancelled) } \\
\text { - MB60 LH (60K-cancelled) }\end{array}$ & $\begin{array}{l}\cdot 250 \mathrm{~K} \mathrm{LOX} \mathrm{[LN]} \\
\cdot 250 \mathrm{~K} \mathrm{LH}\end{array}$ \\
\hline Pump Hot-fire & & & & - $250 \mathrm{~K}$ LOX Pump/PB \\
\hline Powerhead & & & & $\begin{array}{l}\cdot \text {-204K LOX/LH } \\
\cdot 250 \mathrm{~K} \mathrm{LOX/LH}\end{array}$ \\
\hline Engine & & $\begin{array}{l}\cdot \mathrm{H} 2 \mathrm{O} 2 / \mathrm{JP} \text { engine } \\
(6 \mathrm{~K})\end{array}$ & - $60 \mathrm{~K}$ LOX/RPengine & $\begin{array}{l}\cdot \text {-204K R\&D Engine } \\
\cdot \text { - 204K R\&D Dual-engine } \\
\text { - } 700 \mathrm{~K} \text { Flight Engine } \\
\cdot \text { SSME engine }\end{array}$ \\
\hline Stage & & $\begin{array}{l}\cdot 10 \mathrm{~K} \mathrm{H} 2 \mathrm{O} 2 / \mathrm{JP} \text { Stage } \\
\text { (halted) }\end{array}$ & $\begin{array}{l}\cdot 60 \mathrm{~K} \text { LOX HybridStage } \\
\cdot 60 \mathrm{~K} \text { LOX/RP Stage }\end{array}$ & $\begin{array}{l}\text { - Delta } 4 \text { Common Booster } \\
\text { (1 RS68) } \\
\text { - MPTA (3 SSME engines) }\end{array}$ \\
\hline
\end{tabular}

Color key: DOD projects, blue text; commercial, red; and NASA, black.

from the final report by Kirchner et al. Thrust-scale is given in brackets in most cases. The information includes canceled rocket test projects as well. The table excludes non-propulsion test activities.

For the subsequent cost collection and evaluations, the charge codes associated with each project were identified. This charge code is the keystone for cost information collection, and in many occasions there exist multiple charge codes for a test project. The test project manager in collaboration with the team and customer determine how many codes are needed to effectively manage and control the project and its cost. The charge codes were gathered from the financial archives, both hard copy and electronic. Information was cross-checked and augmented by archives of legacy documents.

The archive of legacy documents are comprised of agreements, project requirement documents, project presentations, reports to management, technical papers, and NASA SSC web site information. The search yielded additional information used to construct a table containing the following information: charge code(s), main project 
identification, test stand, test objective, other known project names/codes/description, known project management succession, project status (canceled, completed, active), project successions, notes on test campaigns, and other ancillary relevant facts to complete the record. This table is called the "Business Infrastructure" table. Another table was created to associate the test stands to the test campaigns run on those test stands. Information grouping overall was done in consultation with project managers, engineering staff, and other official personnel.

The Business Infrastructure table is the guide used to put together, in a timeline fashion, the schedule, test activity, and cost information for each project. Thus, Table 1 along with project specific information provide the basis for cost evaluations that are presented in the results sections of this paper.

\section{Development of Test Projects Database}

Tests projects at NASA SSC include small, medium, and large scale test campaigns of various test project durations (i.e. months or years); the highly customized nature of the activities result in many tailored approaches to cost estimating, cost tracking, cost allocations and accrual processes. This was further complicated by ongoing changes in the financial systems as modernization of those systems and other bookkeeping practices evolved through automation, updates and/or adjustments.

As a preamble to the discussion of test project costs, it is necessary to outline first how the test cost database was assembled for this study.

\section{A. Information Sources and Intermediate Databases}

Information used in this study was extracted and distilled from multiple sources, and cross-compared and compiled as needed. Specifically, the sources were:

1) The NASA SSC Quarterly Resources Status Report of the organization's Resources Management Division (known locally as "The Blue Book")

2) Cost Data Warehouse (CDW), an Agency adopted business management tool

3) Space Act Agreements (SAA) for NASA SSC's external customers

4) Requirement documents for the specific test campaigns

5) Rocket Propulsion Test Management Board and Rocket Propulsion Test (RPT) website data on test capability

6) Performing organization's monthly review reports, in the form of briefing charts

7) Associated legacy data on test activity

8) Project presentations

9) Project managers direct interviews

10) Technical expertise of tenured SSC personnel through direct interviews

Although a large amount of information was readily available it could not be used in its original format. Intermediate databases were created to organize information and facilitate data manipulation. Figure 1 illustrates the process followed to capture the information needed for test cost analysis; from data gathering to ultimately test cost analysis.

The project cost history information is derived from Blue Book information (hardcopy) and CDW information (electronic) and it was capture in a spreadsheet document. For the most part cost information from 1997 to 2001 comes from the Blue Book; thereafter, it was obtained from CDW. The process of combining these databases was helpful for cross-comparing and verifying accuracy of actual cost accrual data. If available, cost information used on earlier analyses was included for the purpose of validating the data and the analysis performed at that time. For each project, the efforts performed resulted in development of a project's monthly and cumulative profile of actual cost, from project inception to project closure, as of June 2005, recorded and display on a monthly timeline basis.

Raw test specific information was provided by staff members. The information was sorted by project and by date. Then it was summarized and the resulting number of tests per day, and test seconds per day was transferred to a timeline chart.

Another spreadsheet document captured project schedule information extracted from the performing organization's monthly review reports and official presentations to management. To complement, schedule information from the SAA and/or PRD was included as part of the project schedule history. The SSA and PRD schedule information is planning data and it is included for both historical and comparison purposes. The schedule history, segregated by source and displayed on a monthly timeline, contains actual test data including how many tests, how many seconds, and ancillary notes as to the nature of the test activity. 


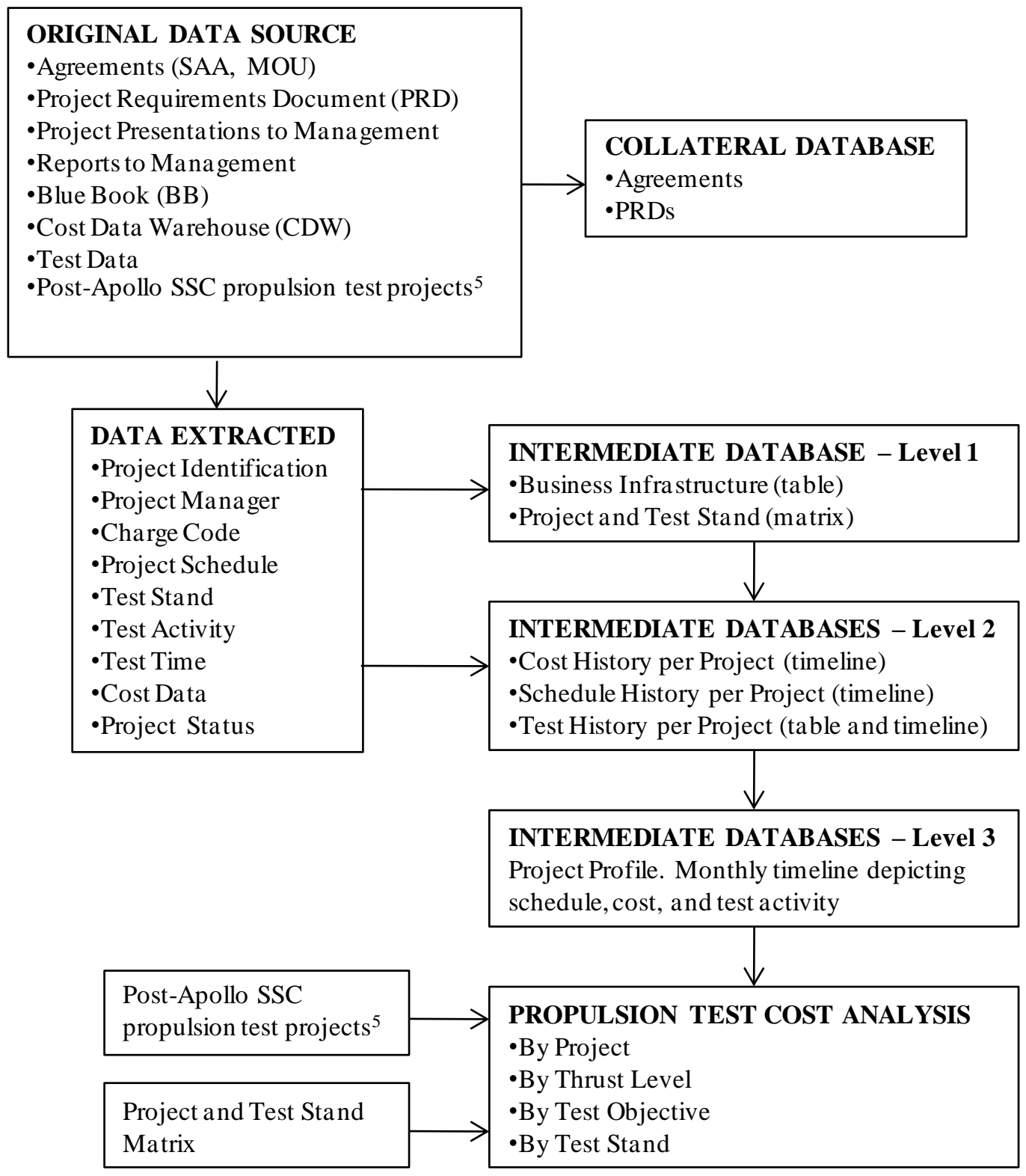

Figure 1. Block diagram to illustrate test cost evaluation approach.

Ultimately a project profile puts all relevant information on a single spreadsheet. This is a record and visual account of projects' actual schedule, cost, and test in a monthly timeline format, all on the same chart, from inception to closeout. The SAA date, or any other official agreement date, is considered the official start date of the project. For all projects there is uncertainty as to the official end and closeout of the project; reason is the nature of costing activities which includes among all others invoices, late-billing and payments, that could occurred many months after the last known test activity of the project. Review of monthly financial activity after the last known test activity lead us to conclude that a period of 6 months after the last known test activity is an adequate timeframe for considering the project closed; thus, any financial transaction performed after the 6 months period is deemed insignificant for the purpose of this study. Actual cost is recorded on a month-by-month basis, as well as in terms of cumulative cost, and percentage cumulative cost. Test activity is denoted by the numbers of tests, the total test seconds; and it is attributed in the month the test happened. As an example, Fig. 2 shows an excerpt of the combined schedule, cost, and timeline for the 75Klbf Thrust Chamber Assembly (75K TCA) test project. In order to 


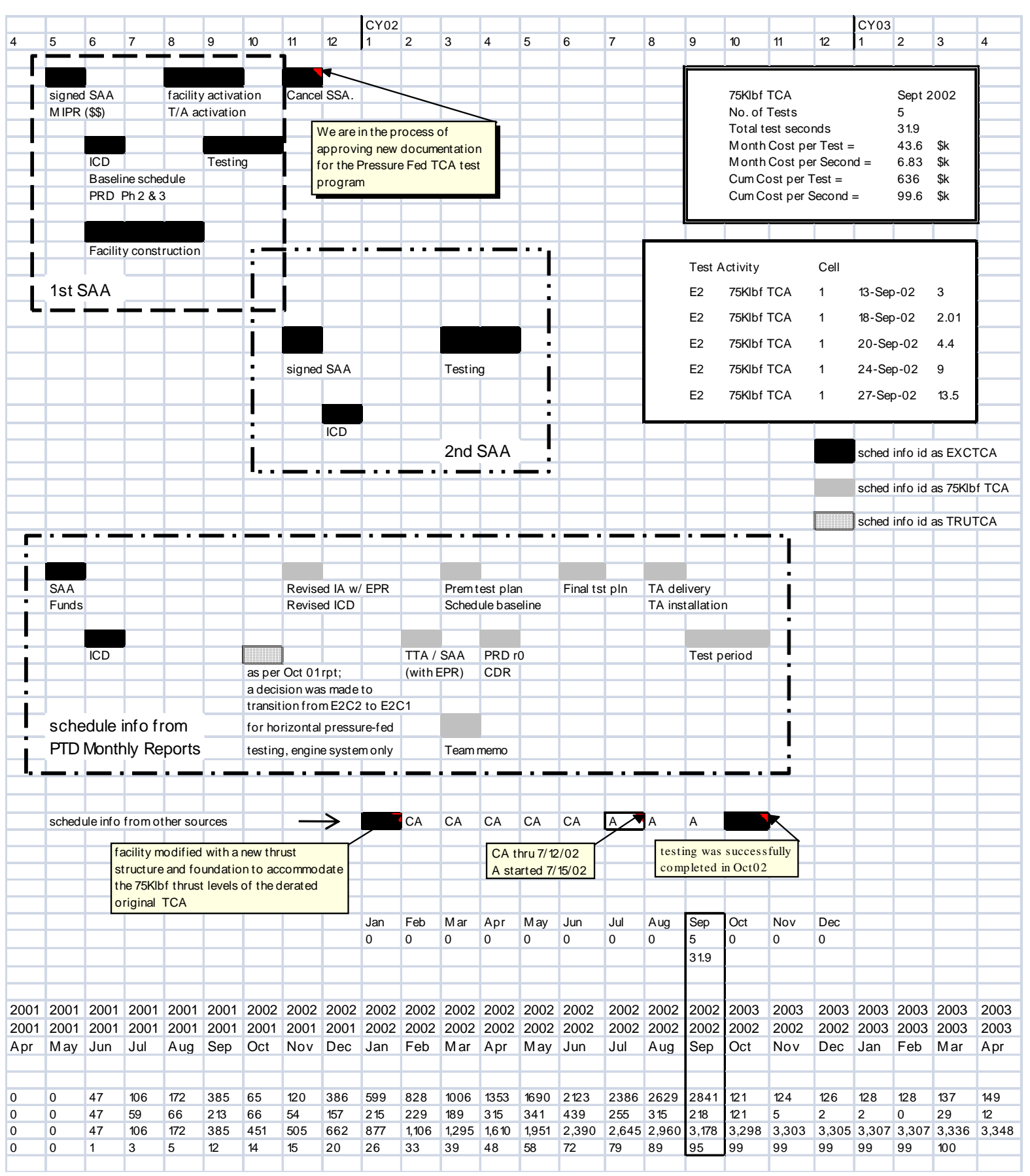

Figure 2. Integrated summary of key events and financial data for the 75K TCA project, as an example.

facilitate the interpretation, a graph for each project is added to the Project Profile database file as well. Figure 5 shows a simplified example of a graphical interpretation for the $75 \mathrm{~K}$ TCA project. As data permits, a variety of test cost evaluations and charts are added to the profile. Examples are: percent cost at different points in the test campaign, average cumulative cost per test, cost envelope per number of test, and so forth.

\section{B. Integrity of Cost Accrual Information}

As noted earlier, cost data was obtained from two sources: the Blue Book and CDW. The Blue Book is the original traditional monthly and year-to-date printout of financial information and given the right criteria it is 
possible to trace cost information back to project inception. NASA SSC began utilizing CDW, a major financial software tool, around year 2002/2003. All project financial information prior to FY 2002 was found to be a single initial value in $\mathrm{CDW}$; thereafter, $\mathrm{CDW}$ information was available on a monthly basis.

One hundred eleven (111) charge codes were indentified from different sources (e.g. presentations, management reports). Cost data was gathered for 84 of them. For 20 of the 84 charge codes with cost data, cost history was constructed by combining/comparing Blue Book information with CDW data. The remaining 64 cost histories were either only in the Blue Book or only in the CDW database.

The first task in the evaluation was to compare the constructed cumulative cost (CCC) of the Blue Book database to the cumulative cost in the $\mathrm{CDW}$ database initialization. (The formula used to calculate percent difference was [[CCC $-\mathrm{CDW}] / \mathrm{CDW}]$ ). Four (4) out of 20 charge codes with constructed cost history showed a cost disparity greater than 5\%. The second task was to examine cases with a cost credit (i.e. negative cost) for a given month. For a variety of reasons, financial transactions to reverse cost are performed and recorded in the financial system. Those transactions are not necessarily recorded against the month when the cost occurred, but the month when the transaction to reverse cost is made. If the total value of the reverse transaction is greater than the cost charged against the charge code in a given month, the resulting actual monthly cost is negative. The examination revealed that from Fiscal Year (FY) 1997 to June 2005, approximately half of the charge codes with cost data showed at least one month with negative actual cost. When grouped by projects, $88 \%$ of the projects experienced at least one month with a negative actual monthly cost. In terms of cost, the absolute value of the negative actual cost was compared against the total cumulative cost per the information recorded in the CDW files. One-fourth (1/4) of the charge codes showed a negative actual cost greater than $1 \%$ of their respective total cost. Only eight percent (8\%) of the charge codes showed a negative actual cost greater than $5 \%$ of their respective total cost. Overall, for all the charge codes considered for the analysis, the total negative actual costs when compared to the total actual cost amounts to less than $2 \%$. These negative costs are actually adjustments and corrections that were made to correct accounts for project and financial changes, fiscal year related modifications, and other such factors. Regardless, for the most part, the cost accrual information is believed to be reliable.

\section{Results and Conclusions}

The results and information presented here is a subset of what is available for discussion and evaluation within the Table 1 grouping, and the financial data itself spans the particular period from 1998 to 2004 for which sufficiently complete information is at hand. Specific test projects are presented as cases to illustrate broader conclusions and trends. While subject to some uncertainty due to changes in financial systems practices, there are several conclusions that can still be reached with confidence regarding the cost of rocket propulsion testing for various types of test articles and test campaigns. An inspection of the cost accrual trends for selected examples should therefore be instructive to those who would plan and budget for future testing campaigns for test articles that are similar or comparable to those in this study.

\section{A. Evaluation of Project Cost}

In Table 2, we list thirteen completed projects along with the number of tests and timeframes for their respective test campaigns; the months correspond to the actual period after testing began and thus exclude many months of precursor test preparations. The final cumulative cost incurred at the test site for executing that project from inception to closeout is shown in $\$ \mathrm{~K}$. Given in order of increasing total cost, the test projects selected for this table are a subset of what is listed in Table 1. In all cases except the last row in the table, the total test series costs include both non-recurring (all stand preparations) and recurring (active testing) costs. Note that the total value of the test effort is in most cases underrepresented in that the accrued cost does not include the labor provided by the test customer, nor does it include any test hardware (test article or test support hardware) that was provided by the test customer or third parties. Nevertheless it is still instructive to examine the costs that are accrued as such.

In general, it is expected that the test project cost is driven by scale of both the test article and test stand, the actual test complexity (hardware, software, test specifics, and more), and the expectations of the test customer regarding its conduct. The examples in Table 2 include small, medium, and large scale test articles/stands. The smallest test articles were the pressure-fed catalyst bed gas generators utilizing a single propellant, hydrogen peroxide. Thrust-scale for the catalyst bed chambers is well under $1000 \mathrm{lbf}$. Mid-size test articles include pressurefed thrust chambers such as a 75K TCA and LOX-fed and peroxide-fed hybrid motors. The larger test articles mentioned included a $200 \mathrm{~K}$ and $250 \mathrm{~K}$ scale LOX/LH engines, and the largest being the LOX/LH 700Klbf thrustscale engine. The engine pumps and powerhead devices were precursor tests to the $250 \mathrm{~K}$ engine system test, and therefore of $250 \mathrm{Klbf}$ thrust-scale. All the examples shown are for R\&D test projects, except for the $700 \mathrm{~K} \mathrm{LOX} / \mathrm{LH}$ 
engine which over the four years was performing flight certification test series on a single test stand. For the five years shown in Table 2, the numbers of tests were 19,72, 21, 16, and 6 respectively. The approximate periods of all the project test campaigns are given for reference, where the actual active testing period (months) is typically a small

Table 2. Test projects sorted by total costs accrued.

\begin{tabular}{|l|c|c|c|}
\hline Test Project Name & $\begin{array}{c}\text { Total Project } \\
\text { Cost } \mathbf{\$} \mathbf{\$ K})\end{array}$ & $\begin{array}{c}\text { Number } \\
\text { of Tests }\end{array}$ & Test Campaign Timeframe* \\
\hline 10K LOX Hybrid & 231 & 4 & Dec 03 \& May 04, Aug 04 \\
\hline H2O2 Catbed & 544 & 418 & Dec. 00, Jun 01, Nov 01-Jan 02 \\
\hline 250K LOX Hybrid & 1,055 & 4 & Jul-Aug 99, \& Jan 02 \\
\hline H2O2 Hybrid & 1,512 & 26 & Jan 00 - Mar 01 \\
\hline 60K LOX Hybrid (stage) & 1,882 & 3 & Jul 00 - Sept 00 \\
\hline 30K Preburner (subscale) & 2,395 & 5 & Sept 03 - Dec 03 \\
\hline 75K TCA & 3,336 & 5 & Sept 02 - Oct 02 \\
\hline 250K-scale LH2 Pump & 5,424 & 16 & Feb 03 - Nov 03 \\
\hline 650K TCA & 6,123 & 16 & Jun 00 - Sept 00 \\
\hline 200K LOX/LH Powerpack & 10,300 & 17 & Oct 99 - Sep 00 \\
\hline 200K LOX/LH Engine & 12,300 & $18 * *$ & Oct 99 - May 00 \& Jul-Aug 01 \\
\hline 650K LOX/LH Stage & 10,698 & 9 & Jan 01 - May 01 \\
\hline 250K LOX P/PB/Pwrhd & 13,611 & 22 & May-Nov 01, Sep-Oct 02, Mar-Jun 03 \\
\hline 650K LOX.LH Engine & 81,471 & 134 & Jun 00 - Aug 04 \\
\hline *Period of active testing (excludes buildup). & $* *$ Only 3 tests were dual-engine version. \\
\hline
\end{tabular}

fraction (one-fifth or less) of the multiple years over which the test project was authorized and executed in terms of its formulate-design-build-operate-demobilize life cycle. Overall, this information set spans almost three (3) orders of magnitude in terms of cost and in terms of the thrust-scale of the test articles.

Several observations are noteworthy within this table. A test article such as for the catalyst bed evaluation test series can undergo a large number of tests (418 in this case) in a relatively short time frame due to its small size and relative simplicity. In fact, on most test days several tests were performed daily for several days with scheduled pauses for data reviews. The number of tests in and of itself is not necessarily a figure of merit. Often simply having a successful test series, even with few tests, is deemed a major success if the hardware design is found to be adequate and hence mitigates design and development risk through early demonstration testing. This was indeed the case with the 75K TCA test series that involved only 5 fully successful tests of a derated heritage engine TCA that was to be fitted onto a simple stage to become a DOD target missile for intercept experiments. Further, for hybrid motors such as the 250Klbf hybrid (liquid cryogenic propellant injected into a solid fuel grain), only a few tests are needed to demonstrate the motor design, and hence only 4 hotfire tests were conducted of this large scale motor.

The case of the $700 \mathrm{~K}$ engine test series is unique in the table, being the only one for a production flight engine. Analogous to the space shuttle main engine, which has occupied SSC test stands for decades (1976-2009), the 700K engine occupies its own test position/stand for multiple years to support the vehicle flight manifest. Thus tests are performed at the rate of 10 to 25 tests per year with an appropriately allocated budget; for the years shown in Table 2 , this budget was approximately $\$ 20 \mathrm{M}$ per year since non-recurring costs had been incurred in prior years.

The case of 250K-scale LOX pump and LH pumps are also unique in that they are the only pump test series represented in Table 2. Rocket engine pump standalone testing may be more complex than thrust chamber testing given the hazards of cryogenic propellants being handled at low feed pressure and high discharge pressure, along with high flowrate and pressure turbine drive gases, and very carefully executed start and shutdown transients. Thus pump testing will often be more costly than testing other combustion devices. When a pump is hot-fired, it is typically a more challenging and expensive test series since two combustion devices are involved, the pump itself and the driving preburner or gas generator. A similarly complex test project was the Aerospike engine testing, where 
a single engine test actually involved 10 simultaneously operating small combustors exhausting to a common nozzle, and the analogous dual-engine engine involved 20 combustors being fed from two sets of turbo machinery. The total cost of $\$ 20.6 \mathrm{M}$ was thus approximately split between the precursor Powerpack testing and the engine testing according to this cost history.

Projects with stand alone single-test-series include the 75K TCA, Peroxide Catbet, 650K TCA, 10K LOX Hybrid, 250K Hybrid, and the 30K subscale preburner as well (once the follow-on main chamber was cancelled). Projects with multiphase test series are all the remaining test projects shown in Table 2.

A trend may be discerned from the same information if presented graphically as in Fig. 3 with respect to thrust-

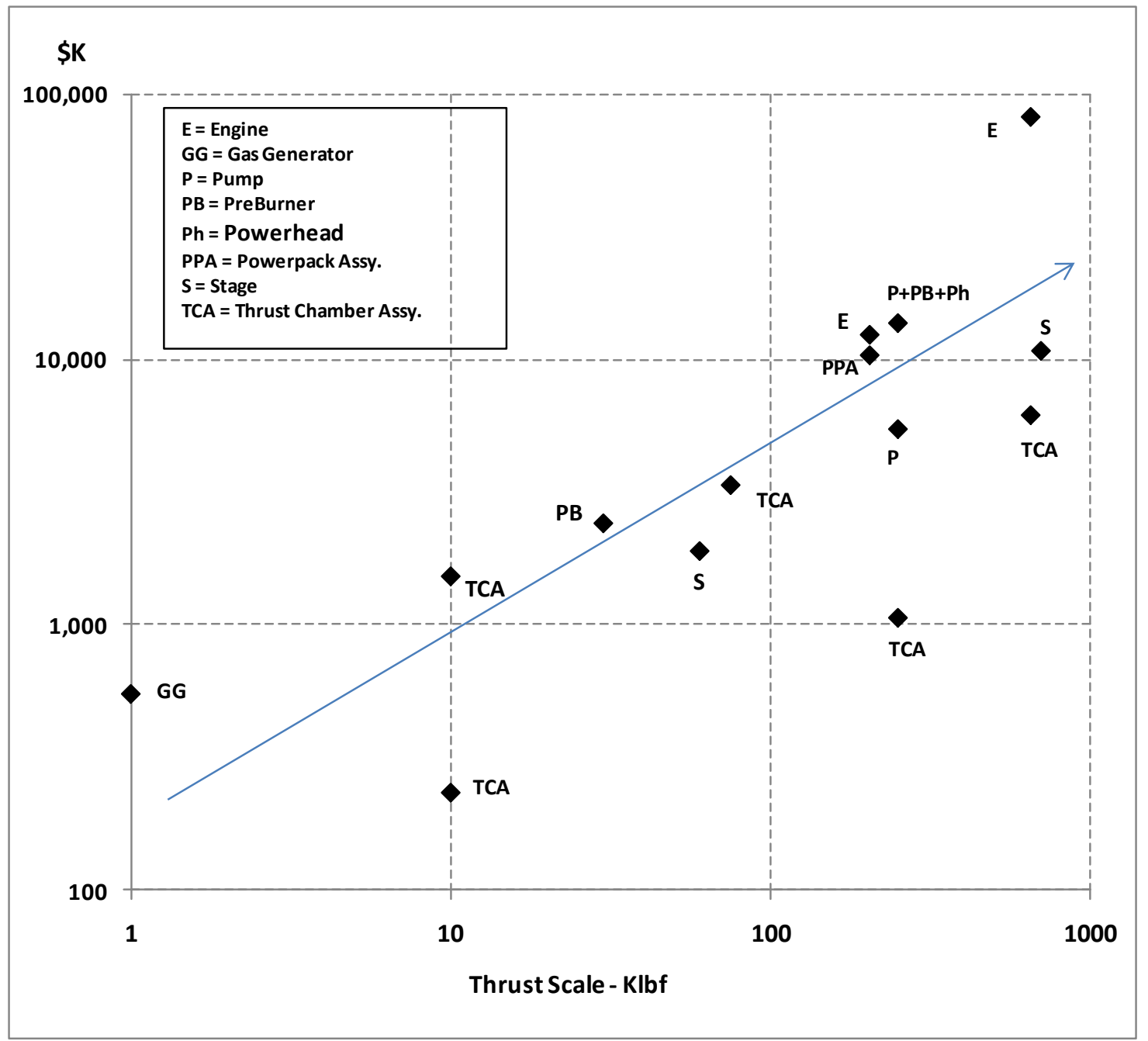

\section{Figure 3. Correlation of test project with thrust-scale.}

scale $\$$. Clearly, the higher the thrust level the greater the cost of the test project. The experience up to approximately 2004 is thus captured in this graphic and can be used as a very approximate guide to anticipate testing costs. Such a trend is also noted from a large amount of bottoms up cost estimates summarized in prior work ${ }^{9}$. The documentation of actual costs is always beneficial, even if somewhat imperfect or incomplete, in order to provide a basis for comparison with future estimates of similar scope.

It is important to further describe the nature of cost estimates and cost drivers. Figure 4 depicts in simplified fashion a breakdown of cost estimates into selected subparts. Three primary components of test project costs are:

1) test facility condition at the time the test project was assigned to the facility and the amount of refurbishment and upgrades needed,

\footnotetext{
"The term "thrust-scale" is preferable to just "thrust" in discussing the trends since; for example, a rocket engine pump for a $250 \mathrm{Klbf}$ engine would be sized for that engine but would only produce a much smaller amount of pure thrust (say $40 \mathrm{Klbf}$ ).
} 
2) project-specific modifications to the test facility in order to accommodate test project requirements and test objectives, and

3) number of tests, and test duration (in terms of seconds or minutes of hotfire time) .

The second and third items are always attributed to the test project, particularly when the test customer is external to NASA. The first item, refurbishment and upgrades, may be cost-shared between the testing organization and the NASA customer or in fact be covered entirely by one of the parties as a strategic improvement to the test stand capability. In the case of Table 2 test projects, the total costs (generally) include all three aspects of the total cost since this is a better measure of the total amount of work that was performed to achieve the test project results.

Several caveats should be mentioned regarding Table 2. First, the costs are reported as they were accrued and collected without any adjustment for inflation. It would be possible to put them on the same baseline financial year if needed; however, these observations are not changed by cost escalation factors. Second, the test projects staffing (design, build and test crews) typically include a time-varying mix of civil servants and support contractors (sometimes predominantly contractor, and sometimes largely civil servants). The overall costs are influenced by the staffing model, but this is not taken into account in presenting this cost information. At this time, it is not possible to recover the exact staffing model for all the above test projects. Third, the test projects shown in Table 1 and 2 were performed for either NASA or external customers, and were estimated to somewhat different cost recovery guidelines per organizational policy and procedures. Such distinctions are not delved into here nor is the data adjusted for the unique arrangements, that occasionally included in-kind assistance (and/or test-specific hardware) provided by the test customers.

The contributions to the test costs (as enumerated in Sec. IIB) may vary by project, in terms of the fraction of cost going to labor, materials, design, propellants, and so forth. There are some aspects of the overall distribution of costs

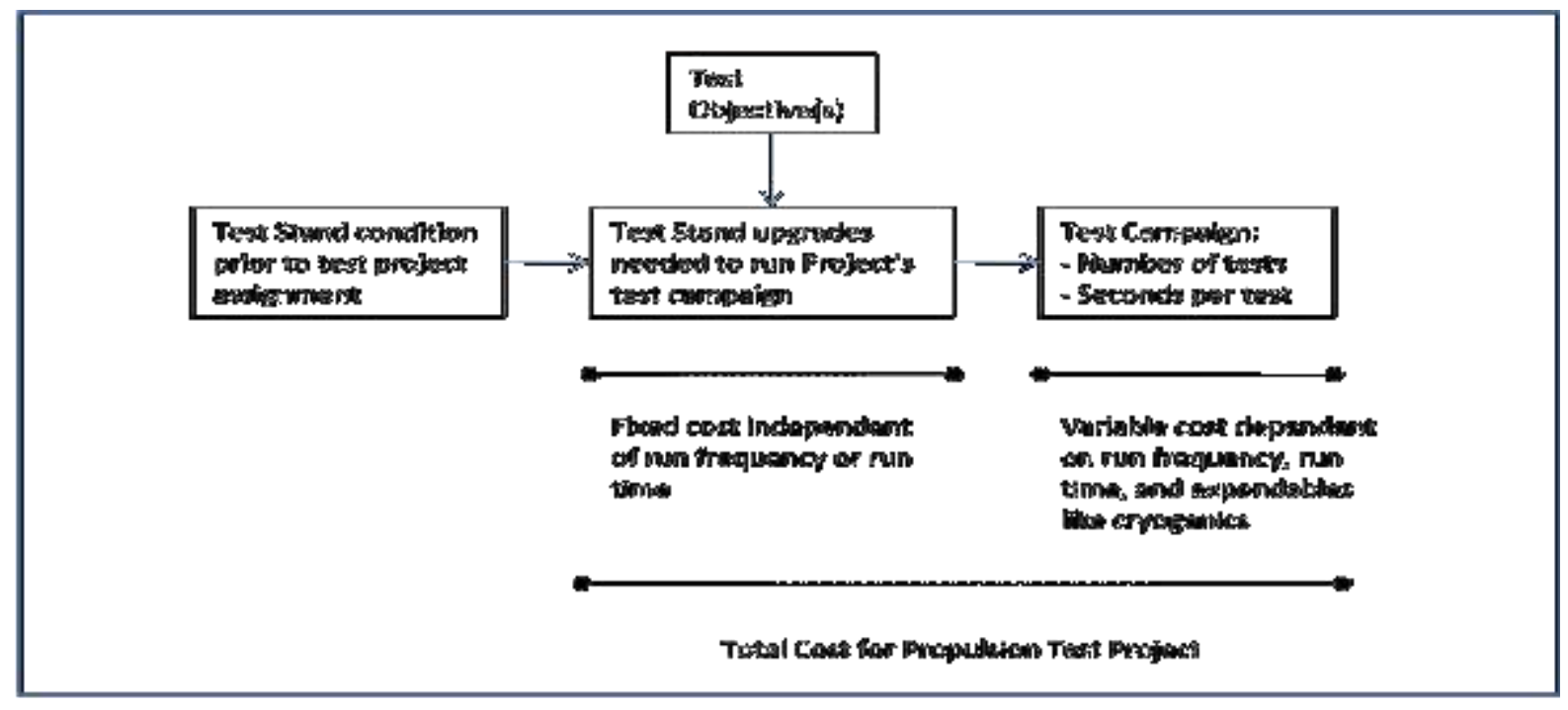

Figure 4. Propulsion tests projects cost components.

that we believe are essentially universal to all test projects. This is illustrated in Fig. 4. The graphic illustrates that given the two major inputs, specific test objectives and test stand initial condition, the factors which drive total test campaign cost are 1) a fixed cost component (non-recurring) needed to get to first test, and 2) a variable cost component (recurring) that continues to accrue for as long as the test campaign goes on. A given test customer implicitly chooses the extent of upgrades/modifications to be made to the stand mostly up front by specifying the necessary test objectives to be met in conducting the test campaign. The test customer also later chooses the amount of variable (recurring) costs, once the test preparations are complete and final test approach/sequence have been established in a way that largely meets objectives within evolving budget constraints, Figure 4 simplifies a very dynamic and interactive process between test customer and test provider, yet serves a reasonable pedagogical model for future test planning. 


\section{B. Representative stand alone single-test-series project (75K TCA)}

In order to better describe the expenditure profile and totals discussed above, the 75K TCA test project is offered as a representative case for illustrating test project life cycle costs. ${ }^{9}$ (Refer to Fig. 2 and Fig. 5) This expenditure profile shows a project's actual schedule, cost, and test in a monthly timeline format, on the single chart. The details of the test project were discussed earlier in Fig. 2. The customer agreement date (SAA in this case, along with an AF MIPR) is considered the official start date of the project. In its absence, any other official document, like the PRD, is used as reference point to mark the start of the project. For all projects there is uncertainty as to the official end and closure of the project. One reason is continued cost accrual activity, which could go on and on for months after the last known test of the project. For purposes of putting together the profile for each project, six (6) months after the last known test is considered the end of the test project. Actual cost data comes from the previously discussed Blue Book and CDW data sources, and is graphed in Fig. 5 month by month in terms of actual and monthly accruals (left axis) and per cent of final cost (right axis).

For this test project, the first official agreement was signed in May 2001 (Refer to Fig. 2), but was later cancelled in November 2001 to be supplanted by a revised one signed the same month. Interestingly, the change was to move the test article from one test stand as a vertical stage test to another stand for horizontal pressured-fed testing engine system only. A problem with the readiness of the stage tanks led to this unexpected situation, relatively early in the effort. At this point, the project has expended over $\$ 505,000$, equivalent to $15 \%$ of its final total cost. Modifications to the test facility, in order to accommodate TA characteristics and meet test campaign requirements for the thrust chamber only testing, were done by July 2002, at which time facility activation commenced. At this point the project had consumed over $75 \%$ of the total project cost. Two months later, test

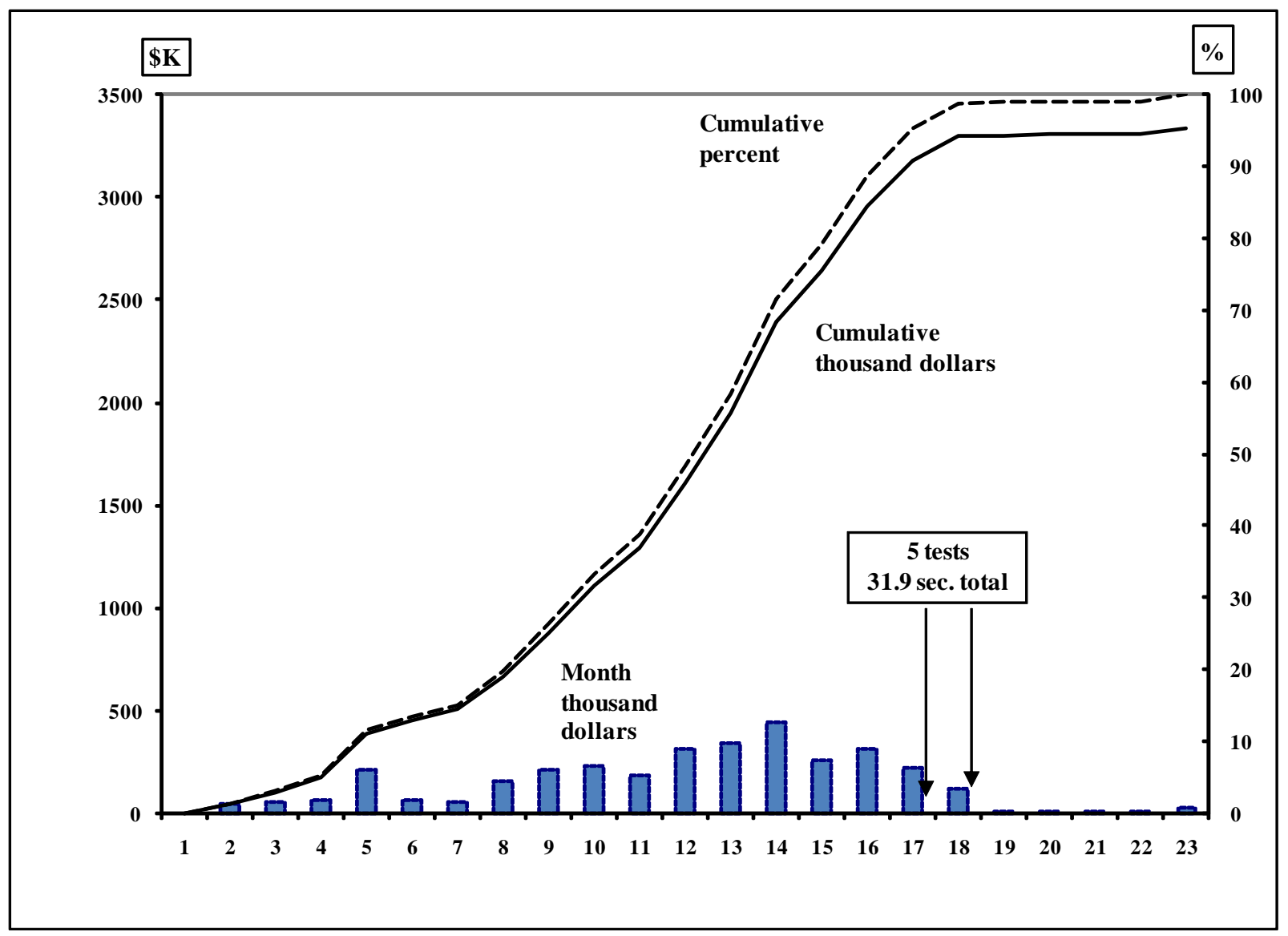

Figure 5. Cost accrual profile for the LR89 chamber.

campaign was completed, consisting of five (5) successful test runs for a total of 31.9 seconds. The most intensive period of activity is actually the months prior to beginning of testing, and this is typical for the test projects reported in this study. For $75 \mathrm{~K}$ TCA, although more tests were originally planned, all essential test objectives had been 
achieved by the fifth test, thus obviating the need for the five remaining planned tests. By the end of the month/test campaign, the project had expended $95 \%$ of the total project cost. Ultimately, the $75 \mathrm{~K}$ TCA test project involved 17 months to go from the first official agreement to the end of the test with a total cost accrual of $\$ 3.34 \mathrm{M}$. Note that the cost of testing here may be said to be $\$ 0.67 \mathrm{M}$ per test in light of the total cost state above. This value however must be viewed in the context that $80-90 \%$ of the costs were non-recurring costs, before a single test point had been achieved. Notably, this particular project fully met its intended scope within negotiated schedule and within its negotiated budget. The complexity of this test project was perhaps in the "median or somewhat less" with respect to others in the group of projects shown in Table 1 and 2.

\section{Representative multiphase test series project (250K LOX/LH staged combustion engine R\&D)}

Whereas the case of the $75 \mathrm{~K}$ TCA involved a single test article with a single test campaign, the $250 \mathrm{~K}$ engine development testing involved testing multiple combustion devices in various configurations in building block fashion over a multi-year period from 2000 to 2004. This case is instructive because it comprises multiple test campaigns towards a single objective of advancing staged-combustion engine technology. At NASA SSC, there were in fact three distinct test articles and the associated test series that were tracked in organizational cost accounts for the oxidizer side development and the fuel side development testing, namely the 1) LOX pump cold-flow test series along with its LOX-rich Preburner and pump/preburner combined hot-fire test series, and, 2) the fuel pump cold-flow test series. The active testing periods are shown in Table 2 for both. The end-objective was risk reduction for the engine test series with all the test articles combined (including a fuel-side Preburner tested at Aerojet facilities in a separate effort). The LOX-side test series involved three phases for the pump, Preburner and finally combined hot-fire series totaling over $\$ 13.6 \mathrm{M}$ upon completion. By contrast, the LH pump only cold-flow test series cost $\$ 5.4 \mathrm{M}$ additional.

Notably, these multiple component testing series were followed by a complete demonstration powerhead featuring everything except the engine nozzle. It is difficult to separate the test efforts by test article since they occupied the same test stand and shared design and operations crews in their individual test project life cycles. To the extent that the fuel pump test series was relatively distinct from the LOX pump testing, it can be said that $\$ 5.4 \mathrm{M}$ was the cost to obtain the technical data from the 6 test points. Multiple attempts (16) were required to achieve these 6 six fuel pump test points, and hence the cost per test could be said to be $\$ 0.9 \mathrm{M}$ per test.

At first glance this may seem an exorbitant price for a single test condition for a $250 \mathrm{Klbf}$ scale pump, and doubling the number of tests would half the cost per test. This circumstance however is better understood in the context of the overall objective. Given the lack of spare hardware, and cost and schedule targets for completion, it was deemed sufficient (by the test customer) to demonstrate the pump with these six tests in order to proceed expeditiously to the complete powerhead demonstration test series with both preburners, both pumps, and a yet untested main combustion chamber still to come.

\section{Recommendation}

With this survey of past $R \& D$ testing costs, and its challenges, the following improvements are suggested for capturing cost of current and future rocket testing. First and foremost, an improved methodology for capturing the cost elements of any given test project is required. This includes labor and materials cost throughout the project's life cycle as well as its consumables usage. To a large extent, NASA SSC has greatly improved methods to capture costs through improved financial systems implemented since 2004. One of the nuances of truly capturing all costs is in defining which costs are to be counted as part of the project and which are not, and maintaining consistency in this regard. (Testing involves not only the test buildup and operations activity but also independent safety reviews, special customer review, and costs to access a wide range of the test site's infrastructure facilities and capabilities on demand).

Further, another major improvement is possible if the capture and archival of cost information is undergirded by information about the business model, so to speak, that was in conducting a given test project. In particular, projects can have assigned personnel that may be part of the cadre of core competency personnel retained by the Agency for corporate memory, at essentially no direct charge to specific test customers. Accounting for such NASA in-kind support, and customer-provided in-kind support, to the project will also better define the overall cost of testing a given test article. 


\section{Closing Remarks}

The data presented here on test project cost ranges over three orders of magnitude, from $\$ 0.5 \mathrm{M}$ to over $\$ 10 \mathrm{M}$, and is examined to better understand testing cost accrual trends at the NASA SSC test facility and potentially other comparable test facilities. In the aggregate the information shows that the test campaign duration itself is generally a small fraction of overall test project life cycle, and that the majority of testing funds are expended in test facility detailed preparations and not the actual testing period. Not surprisingly, test article complexity drives test costs, as well as the engine thrust-scale. The absolute value of the testing costs for the R\&D test examples of this paper are useful as benchmarks for future testing being planned, however, users of the information should be aware that the costs from the test site under represent the total value of effort which typically has significant support from the test article customer personnel and hardware also.

Given such a wide variety of testing, it is unlikely that a single menu of testing costs is practical, even if it is possible. Efforts can be made to categorize the ranges of test costs in terms of scale, and type of test article, however, even sophisticated multivariate correlations will likely fall subject to the variations in market driven costs of material and labor and customer-driven test approaches. The very nature of R\&D testing inherently involves unknowns about the test article and its risk factors, thus driving conservative test approaches to mitigate risk, which in turn affect costs.

Overall, directly applicable experience is the strongest factor in being able to safely conduct a test project and then being able to budget the appropriate amount of schedule and cost for it. Most test customers will have a limited range of information to rely upon with which to budget testing costs and schedules, so the present information set (albeit limited) is provided for the benefit of those who may need such information as a benchmark or guide.

\section{Acknowledgments}

The authors thank Mr. J. Bevis of the NASA SSC Business Office, and Mr. J. Bailey of the NASA SSC Engineering and Test Directorate, at NASA SSC, for their careful review of this paper and their inputs and suggestions towards its content.

\section{References}

\footnotetext{
1 "Test Facilities Capability Handbook - NASA MSFC and NASA SSC," Rocket Propulsion Test Program, January 2007.

${ }^{2}$ Taylor, G., Beckmeyer, D., Warren, Ross, R., Rieder, P., Nichols, R., "Lessons Learned -- 3 Years of H2O2 Propulsion System Testing Efforts at NASA's John C. Stennis Space Center),” 4th International H2O2 Conference, 2001. ${ }^{3}$ Ryan, H., Solano, W., Holland, R., and Rahman, S., "Engineering the Future of Full-Scale Propulsion Testing," AIAA Paper 2001-0746, 39th Aerospace Sciences Meeting, Reno, NV, January 8-11, 2001.

${ }^{4}$ Rahman, S., Gilbrech, R., Lightfoot, R., and Dawson, M., "Overview of Rocket Propulsion Testing and NASA Stennis Space Center," 11th Annual Symposium on Propulsion, Pennsylvania State University, University Park, PA, Nov. 18-19, 1999.

${ }^{5}$ Savona, G., and Hines, M., NASA Stennis Space Center, Personal Communication.

${ }^{6}$ Congiardo, J., "Cost Estimate Trends at E-Complex Test Stands", NASA, SSC Internal Memo VA32M/0058, April, 2002.

${ }^{7}$ Rahman, S. and Hebert, B., "Large Liquid Rocket Testing: Strategies and Challenges," AIAA Paper \#2005-3564, Joint Propulsion Conference, July 2005.

${ }^{8}$ Kirchner, C., Morgan, J., and Rahman, S, "Final Report: NASA SSC Rocket Propulsion Testing Major Statistics," Central Engineering File, Study \#6323-06-007, NASA John C. Stennis Space Center, May 25, 2005.

${ }^{9}$ Thongchua, N., Bright, D., Dracon, S., "Final Report Static Test of a Pressure-Fed LR89 Engine", TRW Launch Test Program Office and USAF, Report \# MDD-02-RSLP-107, December 2002.
} 